\title{
Requirements for Terpene Cyclizations inside the Supramolecular Resorcinarene Capsule: Bound Water and its Protonation Determine the Catalytic Activity
}

\author{
Severin Merget, ${ }^{\dagger}$ Lorenzo Catti, ${ }^{\ddagger}$ GiovanniMaria Piccini, ${ }^{\sharp}$ Konrad Tiefenbacher ${ }^{*} \dagger, \S$ \\ ${ }^{\dagger}$ Department of Chemistry, University of Basel, Mattenstrasse 24a, CH-4058 Basel, Switzerland \\ ¿Current address: Laboratory for Chemistry and Life Sciences, Tokyo Institute of Technology, 4259 Nagatsuta, Midori-ku, \\ Yokohama 226-8503, Japan \\ \#Department of Chemistry and Applied Biosciences, ETH Zurich, c/o USI Campus, Via Giuseppe Buffi 13, CH-6900 \\ Lugano, Switzerland; Facoltàdi Informatica, Istituto di Scienze Computazionali, Universitàdella SvizzeraItaliana (USI), Via \\ Giuseppe Buffi 13, CH-6900 Lugano, Switzerland

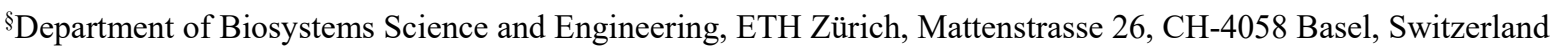 \\ Supporting Information Placeholder
}

\begin{abstract}
The elucidation of the requirements for efficient catalysis within supramolecular host systems is an important prerequisite for developing novel supramolecular catalysts. The resorcinarene hexamer has recently been shown to be the first supramolecular catalyst to promote the tail-to-head terpene cyclization in a biomimetic fashion. We herein present the synthesis of a number of resorcinarene-based macrocycles capable of self-assembly, and compare the corresponding assemblies regarding their catalytic activity in the cyclization of monoterpenes. The assemblies were investigated in detail with respect to a number of properties including the encapsulation of substrate, and ion pairs, the structural incorporation of water and the response to externally added acid $(\mathrm{HCl})$. The results obtained strongly indicate that water incorporated into the hydrogen bond network of the self-assembled structure plays an integral role for catalysis, effectively acting as a proton shuttle to activate the encapsulated substrate. These findings are also supported by molecular dynamics simulations, providing further insight into the protonation pathway and the relative energies of the intermediates involved.
\end{abstract}

\section{Introduction}

The catalytic power and selectivity displayed by natural enzymes still serves as inspiration and role model for many organic chemists working in the broad field of catalysis. ${ }^{1}$ Chemists successfully mimicked some aspects of enzyme catalysis utilizing self-assembled supramolecular host structures. ${ }^{2,3}$ Numerous reactions within different host structures have been reported, however, their catalytic efficiency and selectivity usually do not rival their natural counterparts. In order to close this gap, and to design new, more efficient catalysts, it is essential to understand the fundamental requirements for catalytic activity in these artificial systems.

One of the most frequently applied supramolecular catalyst is the hexameric capsule I (Figure 1a). It self-assembles from six units of resorcinarene 1 and eight molecules of water in apolar media such as chloroform. ${ }^{4} \mathrm{~A}$ number of reactions involving mainly cationic transition states have been reported using structure $\mathbf{I}$ as a catalyst. ${ }^{2 \mathrm{k}}$, ${ }_{2 n, 2 q-s}$ A prime example is the successful catalysis of the tail-to-head terpene (THT) cyclization inside I developed by our group, ${ }^{5}$ which utilizes the supramolecular cavity to enable a reaction that is very difficult to perform in bulk solution. ${ }^{6}$ Terpenes form one of the largest classes of natural products with remarkable structural diversity. Many members exhibit interesting biological activity, making them suitable lead compounds for drug development. ${ }^{7}$ Since most compounds in this class require considerable synthetic effort and are often not available in significant quantity, an efficient method to access these compounds from rather simple precursors would provide a powerful tool to the organic synthetic community. Utilizing capsule I as an aromatic cavity with some similarities to natural cyclase enzymes, we were able to showcase some first examples: A four-step total synthesis of isolongifolene,${ }^{5 \mathrm{c}}$ the first total synthesis of $\delta$-selinene, ${ }^{5 \mathrm{~d}}$ as well as a four step synthesis of the complex tricyclic presilphiperfolan- $1 \beta-\mathrm{ol},{ }^{8}$ which is difficult to access via other means. Interestingly, the closely related hexamer $\mathbf{I I},{ }^{9}$ which is formed from six units of pyrogallolarene 2 (Figure 1b) has been found to be catalytically inactive in THT cyclizations. ${ }^{10}$ The reason for its inactivity, however, remained unknown. We previously speculated that either its low intrinsic acidity, ${ }^{10}$ or its inability to bind ion pairs are the cause for this observation. To clarify this issue, we decided to closely investigate assemblies I and II, as well as the related macrocycles $3-\mathbf{5}$ (Figure 1d), featuring different ratios of resorcinol and pyrogallol units. Additionally, the electrondeficient tetrafluorinated resorcinarene derivative $\mathbf{6}$ was selected. As the main test reaction, we chose the THT cyclization of geranyl acetate (7) to $\alpha$-terpinene (8, Figure 1c, Scheme S1), a reaction which was shown to undergo a "non-stop" cyclization inside $\mathbf{I}^{5 a}$ 
a)
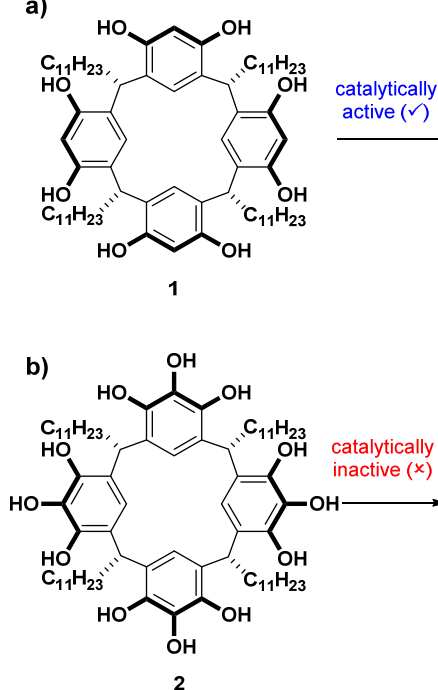
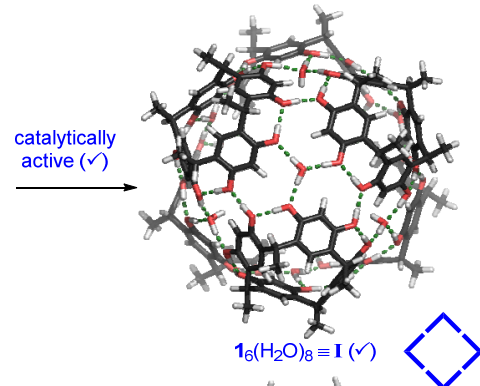

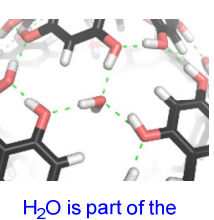

$\mathrm{H}$ bond network
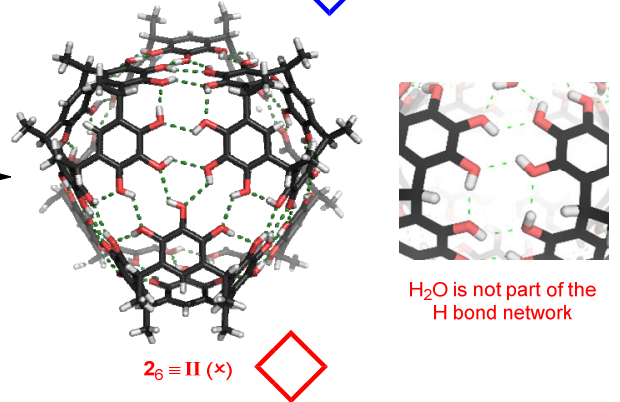

$\mathrm{H}_{2} \mathrm{O}$ is not part of the $\mathrm{H}$ bond network

c) Model reaction: THT Terpene Cyclization
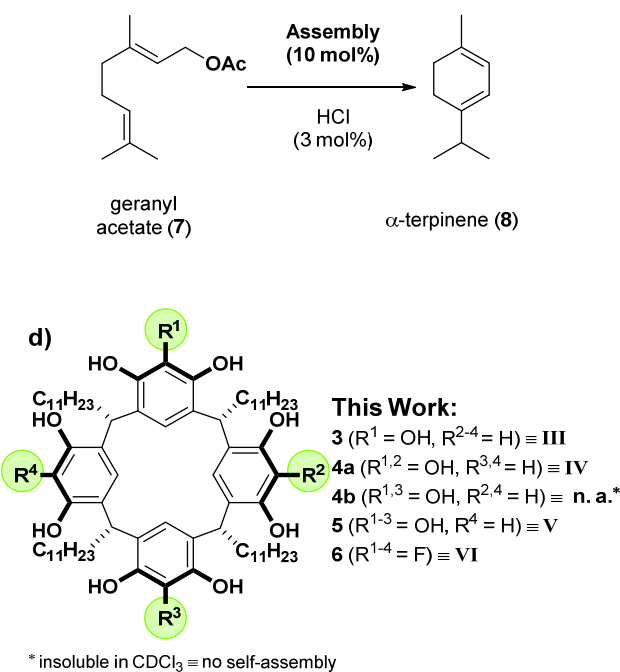

Figure 1: a) Self-assembly of $\mathbf{I}$ from six units of $\mathbf{1}$ and eight water molecules, four of which are not fully saturated within the hydrogen bond network and can function as hydrogen bond donor at the inside of the cavity. b) Self-assembly of II from six units of 2 forming a fully saturated hydrogen bond network without water. c) Tail-to-head terpene (THT) cyclization of geranyl acetate (7) forming $\alpha$-terpinene (8). d) Macrocycles 3 - $\mathbf{6}$ corresponding to assemblies III - VI.

Concerning the prerequisites for catalytic activity, we considered the following steps in the catalytic cycle as potentially decisive (Scheme 1): (a) For a successful conversion inside the molecular capsule, the substrate has to be encapsulated. Therefore, substrate uptake in the different assemblies was explored first. (b) The substrate has to be activated by protonation. ${ }^{5 b}$ Protonation in an apolar solvent like chloroform leads to the formation of ion pairs. Consequently, we next investigated the ability of the assemblies to encapsulate ion pairs. (c) Cationic intermediates and transition states have very likely to be stabilized via cation- $\pi$ interactions. Accordingly, we included an electron-deficient derivative (i.e. 6) featuring four additional fluorine substituents in the study as it should display reduced cation- $\pi$ stabilization.

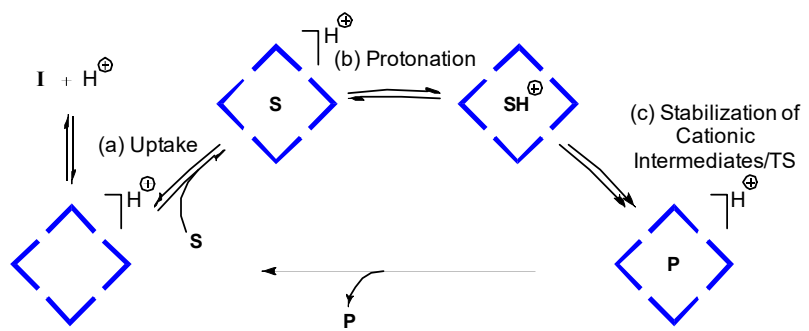

Scheme 1: Potentially decisive steps of the catalytic cycle; $\mathbf{S}=$ Substrate, $\mathrm{TS}=$ Transition States, $\mathbf{P}=$ Products.

Here, we report efficient synthetic routes to macrocycles $3-6$ (Figure 1d), their ability to self-assemble to the hexameric capsules III - VI, and provide evidence that water being incorporated into the hydrogen bond network of the corresponding assemblies plays a crucial role for the efficient catalytic cyclization of monoterpenes.

Aside from compound $\mathbf{4 b}$, featuring two distal pyrogallol units, all macrocycles were soluble in chloroform, and self-assembled to hexameric capsules related to I and II. DOSY-NMR experiments ${ }^{15}$ provided diffusion values for the new assemblies very close to

\section{Results and Discussion}

Synthesis of Macrocycles $3-6$ and Investigation of their Self-assembling Properties

First, it was necessary to develop a reliable route to access the macrocycles 3-6, in pure form on a preparative scale (Scheme 2). While there has been a report about directly cyclizing different ratios of resorcinol and pyrogallol with the corresponding aldehyde to obtain macrocycles $\mathbf{3}-\mathbf{5}$ by Atwood et al., these reactions yielded very complex mixtures that were not separable in our hands. ${ }^{9 \mathrm{~d}}$ To circumvent these separation issues, a more controlled route utilizing tetrabromo-derivative 9 was developed (Scheme 2). Compound $\mathbf{9}$ is accessible via literature procedures in two steps from resorcinarene 1 on decagram scale. ${ }^{11}$ It was partially debrominated by treatment with specific amounts of $n$-butyllithium, and subsequently methanol. The remaining aryl bromides were then converted in situ into phenolic moieties using $n$-butyllithium and trimethylborate followed by the addition of $\mathrm{NaOH} / \mathrm{H}_{2} \mathrm{O}_{2}{ }^{12}$ This yielded biased mixtures of the octamethylated compounds $\mathbf{1 0}-\mathbf{1 2}$ which were separable by column chromatography. The tetrafluorinated compound $\mathbf{1 3}$ was accessed in a similar way from $\mathbf{9}$ using halogen-lithium exchange followed by the addition of the electrophilic fluorine reagent $N$-fluorobenzenesulfonimide (NFSI). ${ }^{13}$ The removal of the methyl protecting groups was achieved by stirring in the presence of boron tribromide at room temperature for several days, ${ }^{14}$ yielding compounds $\mathbf{3 - 6}$ in moderate to good yields and in analytically pure form (see SI Chapter 11). The products were recrystallized and subsequently washed with a $\mathrm{H}_{2} \mathrm{O} / \mathrm{MeOH}$ mixture in order to remove any acid traces (see SI for details).

those of assemblies I and II (see Table S2). Self-assembly was further corroborated by the fact that assemblies III - VI show uptake of ammonium salts (i.e. $\mathrm{NBu}_{4} \mathrm{Br}(\mathbf{1 4})$, Figure S17) indicated by the 
strong upfield shift of the guest protons due to the aromatic shielding effect. We, therefore, concluded that the obtained macrocycles form assemblies resembling the structures of I and II. However, it has to be noted that in the case of the assemblies III $-\mathbf{V}$, the structures are not as symmetric and clearly defined as in I and II. Due to the lower degree of symmetry of the macrocycles, different isomers of hexameric capsules are formed. The broad signals in the ${ }^{1} \mathrm{H}-\mathrm{NMR}$ spectra recorded in $\mathrm{CDCl}_{3}$ suggest that there is more than one assembly present and that these are interconverting. Solid state structures could not be obtained since crystal formation is hindered by the dynamic nature of the assemblies, and the long flexible alkyl chains. Besides, crystal structures do not always correlate with structures present in solution as illustrated by macrocycle $\mathbf{5}$. While we cannot exclude the presence of the previously reported, X-raybased donut shaped structure, ${ }^{9 \mathrm{~d}}$ none of the experiments we carried out hinted at such an assembly in solution. In the case of assembly VI, the NMR spectrum closely resembles that of the resorcinarenebased capsule I, indicating a similar structure. (see SI for the energy optimized structure)

\section{Evaluation of the Catalytic Activity in the Cyclization of Monoterpenes}

With assemblies I - VI in hand, the cyclization of geranyl acetate (7, Figure 1c) as the model reaction was investigated employing the optimized conditions reported previously by our group for assembly $\mathbf{I}^{5 \mathrm{~b}} \mathrm{HCl}$ is added as a co-catalyst, which, unable to catalyze the reaction by itself, works in a synergistic fashion with the assembly. As reported by us, ${ }^{10}$ no reaction was observed with assembly II (Figure 2e), while assembly I (Figure 2a) catalyzed the formation of $\alpha$-terpinene (8) from acetate 7 in $30-35 \%$ yield. The reaction proceeds in good selectivity with other common cyclization products (Figure 2g) such as eucalyptol (15), terpinolene (16), limonene (17), $\gamma$-terpinene (18) and isoterpinolene (19) being only formed in minor quantities $(<10 \%$ yield). Assembly III (Figure $2 \mathrm{~b}$ ), formed from monomer 3 , featuring one additional hydroxyl group compared to resorcinarene $\mathbf{1}$, also displayed catalytic activity and likewise yielded $\alpha$-terpinene $(\mathbf{8})$ as the main product, albeit in a lower yield. When employing assembly IV (Figure 2c), the conversion of substrate remained significant, but the overall yield of cyclization products dropped significantly. We attribute this fact to a side reaction in which phenolic groups of $\mathbf{4 a}$ react with the highly reactive cationic intermediates of the cyclization reaction. This was also observed for $\mathbf{I}$ in an earlier report and confirmed by isolation..$^{5 a}$ In the current study, these alkylation products were detected by ESI-MS analysis of the reaction mixtures (see Figures S8 - S13) in the cases of the assemblies I, III and IV. Interestingly, assembly $\mathbf{V}$ (Figure 2d) with three pyrogallol units showed no catalytic activity in this cyclization reaction. The reaction in the presence of assembly VI (Figure 2f) featuring subunits with fluorine substituents proceeded very slowly. Similar results were obtained when the reaction was conducted with the intrinsically more reactive nerol (20) as the substrate (see Figure S2 for the reaction profiles). Assemblies I, III and IV showed comparable behavior with only small differences in product selectivity. Initially, mainly $\alpha$-terpineol (25) is formed, which is then further converted to eucalyptol (15), the major product after 72 hours $(30-38 \%$ yield). In the case of the fluorinated assembly VI, the formation of $\alpha$-terpineol (25) in combination with traces of eucalyptol (15) (4\% after 72 hours) indicates a reaction profile similar to the one of assembly $\mathbf{I}$, with the conversion being, however, again significantly slower. Assembly II shows no activity, while the closely related assembly $\mathbf{V}$ leads to considerable conversion $(60 \%$ conversion after $72 \mathrm{~h}$, Table 1 , entry 1$)$. At first glance, this seemed surprising since assembly $\mathbf{V}$ showed no conversion with geranyl acetate (7). In order to understand this observation, control experiments with assembly $\mathbf{V}$ were conducted (Table 1). No conversion was observed in the absence of $\mathbf{V}$ with $\mathrm{HCl}$ present (entry 2). Blocking assembly $\mathbf{V}$ with tetrabutyl ammonium bromide (14) did not halt the reaction completely (13\%, entry 3$)$, indicating that the reaction is not only taking place within the cavity in that case. This was further corroborated by substituting assembly $\mathbf{V}$ with 4-hexyl resorcinol (21) which also led to some conversion of nerol (20) (10\%, entry 5) after three days. Moreover, the product distribution of entry 1 indicated that the reaction likely takes place outside/on the outer surface of the capsule.

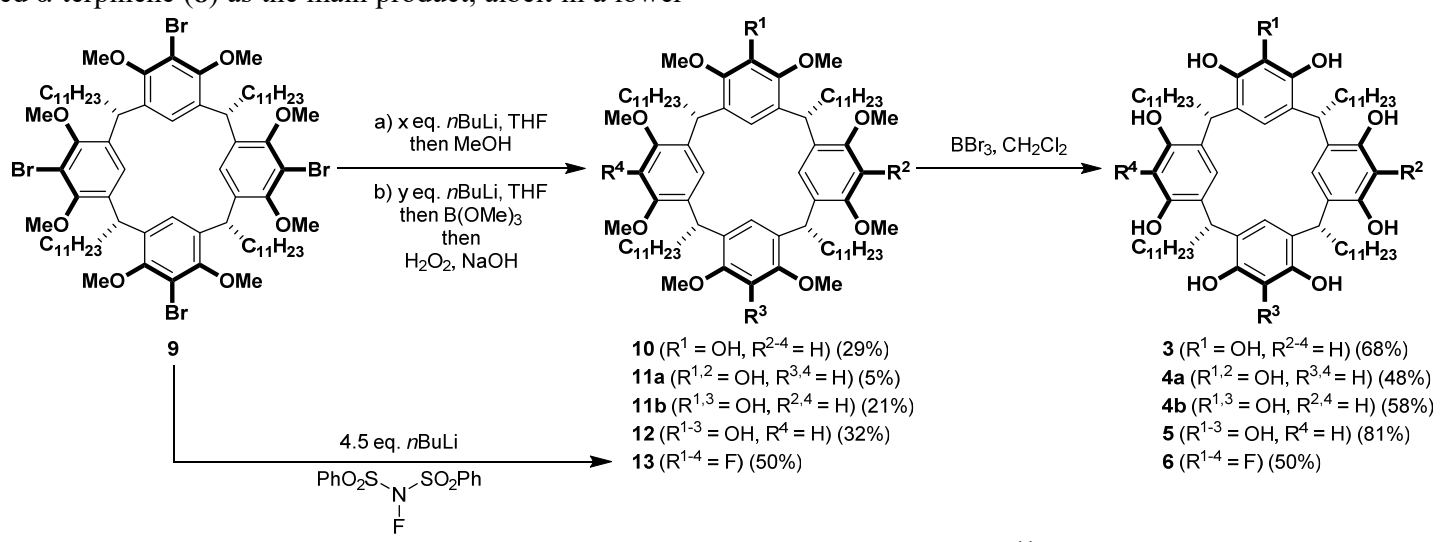

Scheme 2: Synthesis of the macrocycles $3-6$ starting from the literature known compound $\mathbf{9} .{ }^{11}$ 

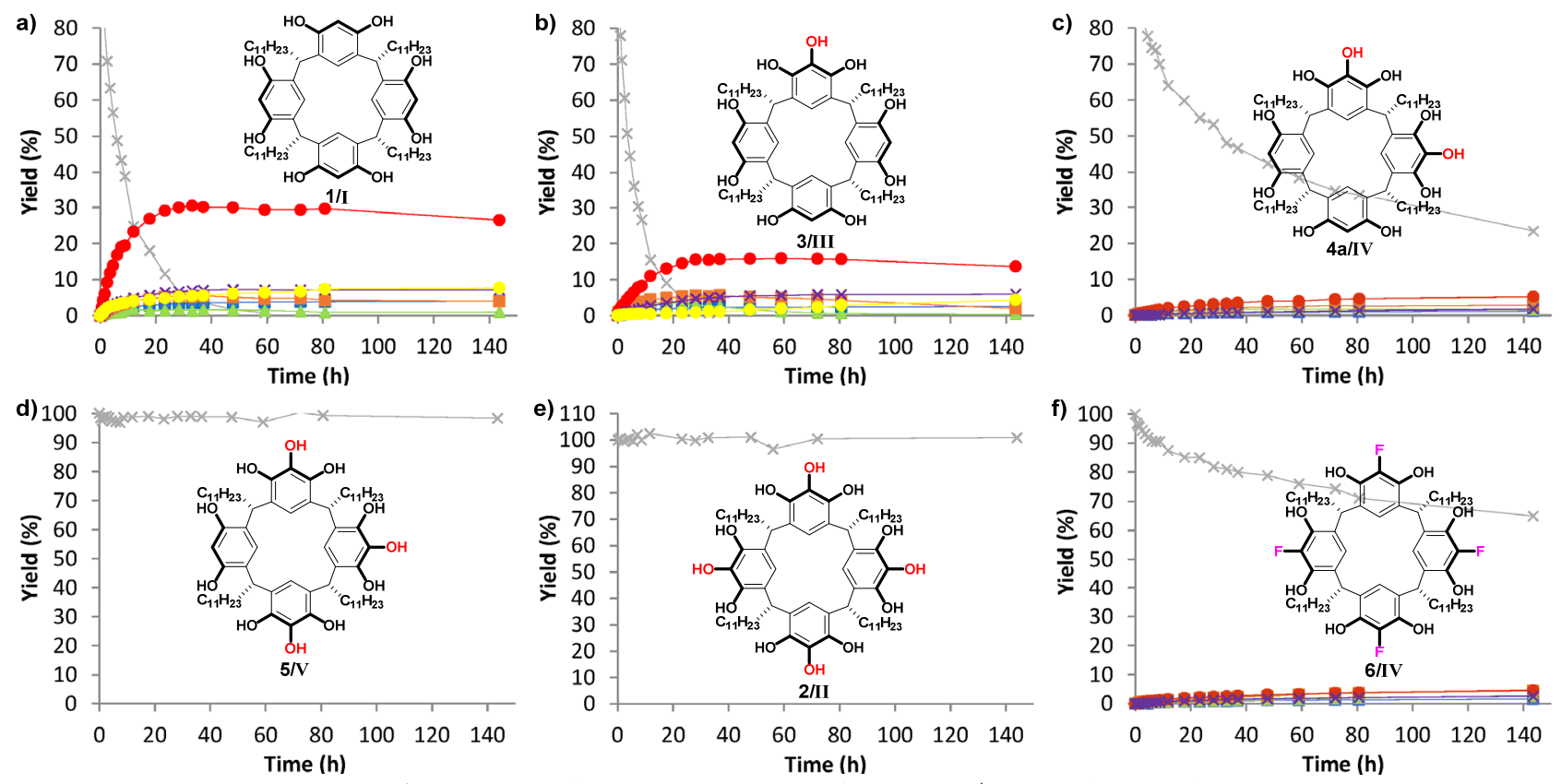

g)
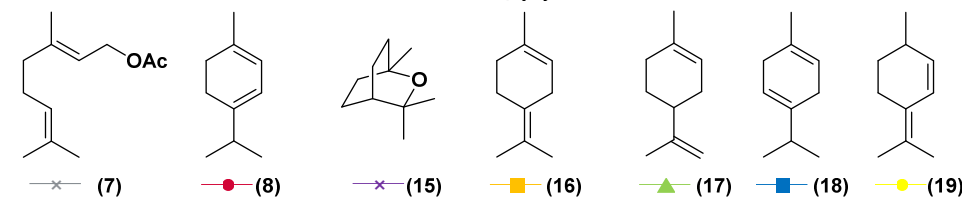

h) Additional substrates and guests:<smiles>CC(C)=CCCC(C)=CCO</smiles>

(20)<smiles>CC(C)=CCCC(C)=CCO</smiles>

(22)<smiles>CC(C)=CCC(C)(O)C(C)(O)C(=O)O</smiles>

(23)<smiles>CC(C)=CCOC(=O)CCl</smiles>

(24)<smiles>CC1=CCC(C(C)(C)C)CC1</smiles>

(25)<smiles>CCCC[N+](CCCC)(CCCC)CCCOCC(C)CCC(C)C</smiles>

(26)
$X=B r(14)$
$X=O T f(27)$
$X=B_{4}(28)$

Figure $2 \mathrm{a}-\mathrm{f}$ ): GC-based reaction profiles of assemblies I, III, IV, V, II and VI with geranyl acetate (7) as substrate (reaction conditions: $33.3 \mathrm{mmol} / \mathrm{L}$ of 7, $10 \mathrm{~mol} \%$ assembly, $3 \mathrm{~mol} \% \mathrm{HCl}$, in $\mathrm{CDCl} 3$ at $30^{\circ} \mathrm{C}$ ). g) Substrate 7 and reaction products. h) Additional substrates and guests.

Table 1: Control experiments for the nerol (20) cyclization with assembly $\mathbf{V}$ under standard reaction conditions. (33.3 $\mathrm{mmol} / \mathrm{L}$ of $\mathbf{2 0}$, $3 \mathrm{~mol} \% \mathrm{HCl}$, in $\mathrm{CDCl} 3$ at $30^{\circ} \mathrm{C}$ )

\begin{tabular}{|c|c|c|c|}
\hline Entry & $\begin{array}{l}\text { Catalyst } \\
(\mathrm{mol} \%)\end{array}$ & $\begin{array}{l}\text { Additive } \\
\text { (mol\%) }\end{array}$ & $\begin{array}{c}\text { Conversion (\%) } \\
\text { (72 h) }\end{array}$ \\
\hline 1 & $\mathbf{V}(10)$ & - & 60 \\
\hline 2 & - & - & - \\
\hline 3 & V (10) & $n-\mathrm{Bu}_{4} \mathrm{NBr}(14)(15)$ & 13 \\
\hline 4 & - & $n-\mathrm{Bu}_{4} \mathrm{NBr}(14)(15)$ & - \\
\hline 5 & - & $(21)(240)$ & 10 \\
\hline
\end{tabular}

${ }^{[a]}$ Determined by GC
The main products are limonene (17) and $\alpha$-terpineol (25), which are also formed in regular solution experiments under acidic conditions, ${ }^{16}$ and in the presence of 4-hexyl resorcinol (21). Additionally, the absence of eucalyptol (15) which is usually formed to a significant degree when the reaction takes place within the assembly (i.e. in assembly I) indicates a conversion outside the assembly. Taken together, these results indicate that in this case the reaction is taking place mainly outside/on the outer surface of assembly $\mathrm{V}$ presumably via hydrogen bonding (Table 1 , entry 5 ), due to the higher reactivity of nerol (20). It should also be noted that assembly $\mathrm{V}$ proved to be an inefficient catalyst in the cyclization of other substrates (Figure $2 \mathrm{~h}$ ) such as geraniol (22), linaool (23), neryl chloroacetate (24), all of which showed less than $15 \%$ conversion after 72 hours. In the cases where traces of product were detected, these correspond again to limonene (17) and $\alpha$-terpineol (25), indicating that the conversion is likely taking place in solution rather than inside V (Figures S4 - S6). In summary, the cyclization studies revealed that assemblies I, III, IV and VI are active supramolecular catalysts for the THT cyclization, while II and $\mathbf{V}$ are inactive. 


\section{Uptake Studies}

Substrate uptake is a prerequisite for catalysis inside the capsule. In order to elucidate a potential correlation between catalytic inactivity and inability of substrate uptake, a set of NMR experiments was performed. For this purpose, the saturated substrate analogue $\mathbf{2 6}$ (Figure 2h), which is not converted in the presence of assemblies I - VI and $\mathrm{HCl}$, was employed. Host and guest solutions in chloroform were mixed in the ratios used for cyclization $(1: 10)$ in the presence of $\mathrm{HCl}$ at $0{ }^{\circ} \mathrm{C}$ and immediately submitted to NMR spectroscopy. The samples were then stored at $30^{\circ} \mathrm{C}$ and monitored by ${ }^{1} \mathrm{H}$-NMR. Guest uptake over time was determined via ${ }^{1} \mathrm{H}-\mathrm{NMR}$ analysis (Table 2), by comparison of the respective assembly signals (internal standard) and the signal of 'free' $\mathbf{2 6}$. The values given are calculated assuming that directly after addition no encapsulation is observed. Table 2 shows that the amount of non-encapsulated substrate $\mathbf{2 6}$ is decreasing with time in all cases, indicating a gradual encapsulation of $\mathbf{2 6}$ by all assemblies to varying degrees (for full details see Tables S3-S8). This is further supported by the appearance of small signals below $0.5 \mathrm{ppm}$ in the respective ${ }^{1} \mathrm{H}$ NMR spectra, which continued to increase when the samples were monitored over a longer period of time (see Figures S14, S15). All assemblies investigated, including the catalytically inactive assemblies II and V, showed some uptake of guest 26. A direct correlation between catalytic activity and encapsulation of substrate could, therefore, not be established.

Table 2: Encapsulation of substrate analogue $\mathbf{2 6}$ by assemblies IVI under reaction conditions. (33.3 $\mathrm{mmol} / \mathrm{L}$ of $\mathbf{2 6}, 10 \mathrm{~mol} \%$ assembly, $3 \mathrm{~mol} \% \mathrm{HCl}$, in $\mathrm{CDCl} 3$ at $30{ }^{\circ} \mathrm{C}$ )

\begin{tabular}{cccc}
\hline Entry & Assembly & $\begin{array}{c}\text { Encapsulation } \\
\text { after } \mathbf{~ h ~ ( \% ) ~}^{[\mathrm{a}]}\end{array}$ & $\begin{array}{c}\text { Encapsulation } \\
\text { after } \mathbf{4 8} \mathbf{~ h}(\%)^{[\mathrm{a}]}\end{array}$ \\
\hline 1 & I & 1.3 & 3.1 \\
2 & III & 1.0 & 1.4 \\
3 & IV & 0.3 & 0.7 \\
4 & V & 0.5 & 1.5 \\
5 & II & 0.6 & 1.0 \\
6 & VI & 0.3 & 2.3 \\
\hline
\end{tabular}

[a] Determined by ${ }^{1} \mathrm{H}-\mathrm{NMR}$ Integration

\section{Encapsulation of Anions/Ion Pairs}

After encapsulation, protonation of the substrate with $\mathrm{HCl}$ in the apolar solvent chloroform will form an ion pair. Therefore, we investigated the ability of the different assemblies to encapsulate ion pairs. While I readily encapsulates ammonium salts, such as tetrabutylammonium bromide (14), the encapsulation of anions in assembly II has been shown to be energetically unfavorable. ${ }^{10}$ The binding of anions can be easily investigated with ${ }^{19} \mathrm{~F}-\mathrm{NMR}$ when utilizing fluorine containing anions (e.g. triflate). Figure 3 shows the ${ }^{19} \mathrm{~F}-\mathrm{NMR}$ spectra of the assemblies $\mathbf{I}$ - VI in the presence of 1.0 equivalent of tetrabutylammonium triflate (27). In all cases, the presence of the assembly causes a shift and broadening of the signal corresponding to the triflate anion, with the sole exception being assembly II where no effect on the triflate signal was observed. When employing tetrabutylammonium tetrafluoroborate (28), similar results were obtained (Figures S17, S18). Importantly, the catalytically inactive assembly $\mathbf{V}$ is able to bind ion pairs in contrast to the inactive assembly II. In conclusion, the ability to encapsulate ion pairs does not correlate with the catalytic activity of assemblies I - VI.

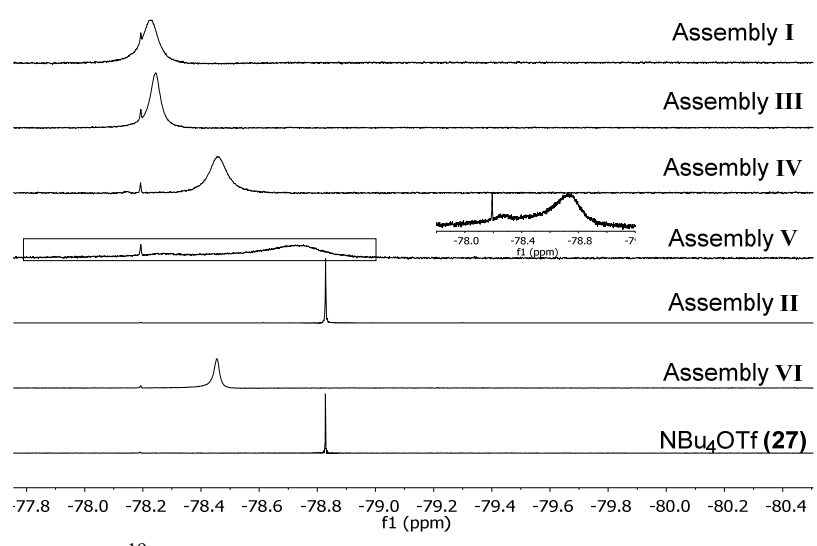

Figure 3: ${ }^{19} \mathrm{~F}-\mathrm{NMR}$ spectra of assemblies I - VI $(3.33 \mathrm{mmol} / \mathrm{L})$ in the presence of 1.0 eq. of $\mathrm{NBu}_{4} \mathrm{OTf}(27)$ in $\mathrm{CDCl}_{3}$.

\section{Protonation Studies}

During the cyclization studies, we recognized that some ${ }^{1} \mathrm{H}-\mathrm{NMR}$ signals of several assemblies changed upon the addition of $\mathrm{HCl}$ as co-catalyst. Therefore, this phenomenon was investigated in more detail. For this purpose, chloroform solutions of the assemblies I VI were titrated with $\mathrm{HCl}(3.33 \mathrm{mmol} / \mathrm{L}$ of assemblies I - VI, 0.0 -1.0 eq. $\mathrm{HCl}$ added to the same sample). The results (Figure 4) show that in four cases (I, III, IV and VI, Figure $4 \mathrm{a}-\mathrm{c}$ and f) the signals corresponding to the phenol groups as well as the water signal broaden with increasing amounts of $\mathrm{HCl}$. We attributed these changes to the protonation of the assemblies by the external acid. In contrast, the signals corresponding to the phenol groups of the assemblies II and $\mathbf{V}$ (Figure 4d, e) remain unaffected by the added acid and also the water signal only broadens to a very small extent when compared to the other assemblies (Figures $4 a-c$ and f). This indicates that assemblies II and $\mathbf{V}$ are not protonated by the external acid, at least on the ${ }^{1} \mathrm{H}-\mathrm{NMR}(500 \mathrm{MHz})$ time scale. ${ }^{17}$ Importantly, the observed protonation of the host correlates well with the observed catalytic activity of the respective assemblies in the cyclization of monoterpenes.

\section{Water as Integral Part of the Assembly}

As mentioned before, the main structural difference between assemblies I and II is the incorporation of water into the 

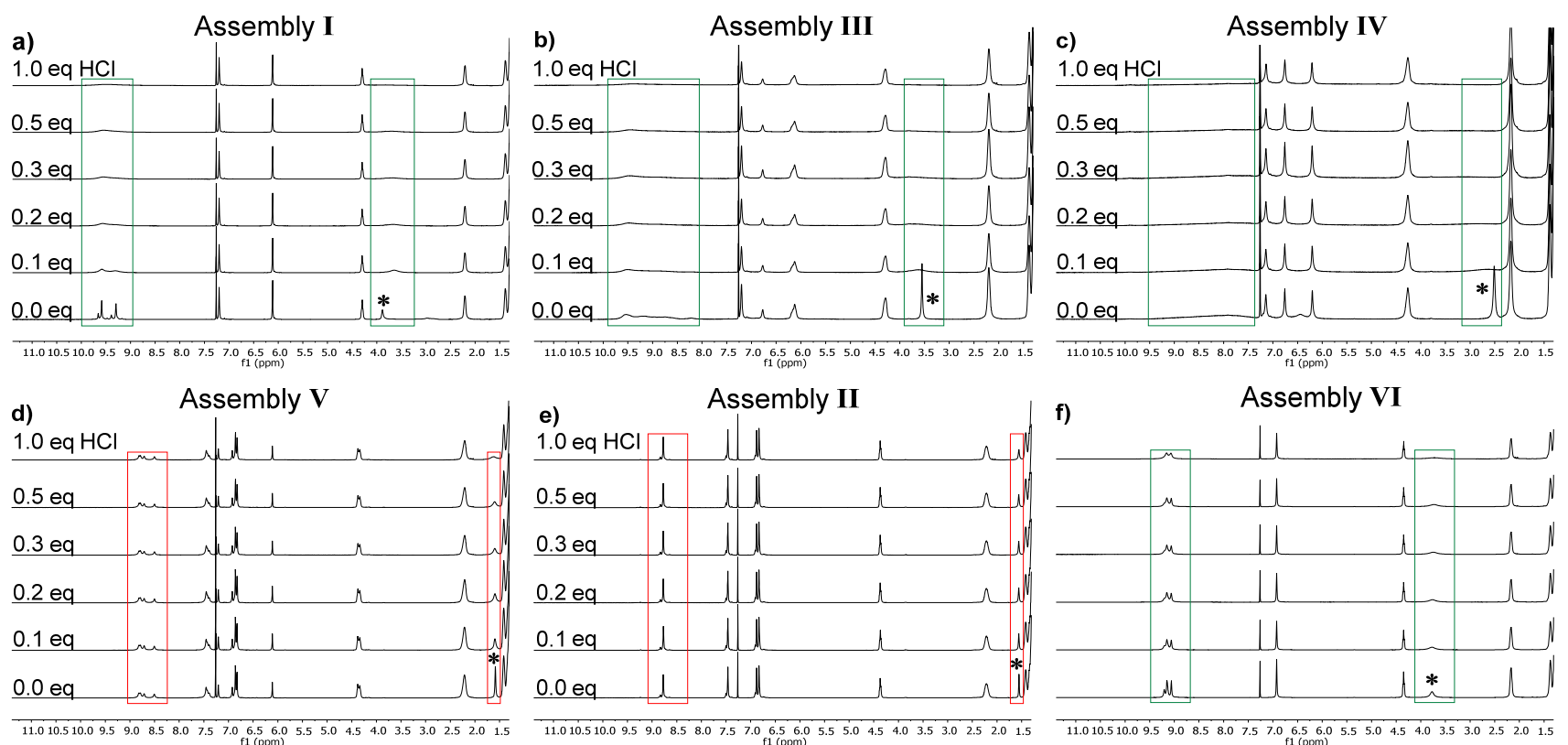

Figure 4: a - f) NMR titration of the respective assembly $(3.33 \mathrm{mmol} / \mathrm{L})$ with $\mathrm{HCl}(0.0-1.0$ eq.). Representative signals corresponding to phenol moieties and water are highlighted (green for catalytically active, red for catalytically inactive). The water signals are marked with an asterisk $(*)$.

hydrogen bond network. This can be directly observed in the ${ }^{1} \mathrm{H}-\mathrm{NMR}$ spectra in $\mathrm{CDCl}_{3}$, where the water signal in the presence of $\mathbf{I}$ is significantly downfield shifted, while it remains largely unaffected with II (Figure $4 \mathrm{a}$ and e, 0.0 eq. $\mathrm{HCl}$ ). The shift is associated with the incorporation of water into the capsular hydrogen bond network. ${ }^{18}$ Water being incorporated into the assembly and 'free' water in solution are in fast exchange on the ${ }^{1} \mathrm{H}-\mathrm{NMR}$ time scale, therefore, only one averaged water signal is observed. The magnitude of the downfield shift depends on the total amount of water present in the solution; with a low water content leading to a stronger shift. Cohen et al. reported a method based on DOSY-NMR experiments to determine the water content in $\mathbf{I}$ and $\mathbf{I I} .{ }^{18}$ If water is not part of the assembly, like in II, its diffusion value is independent of the total water amount in the sample (e.g. assembly II, Figure 5e).
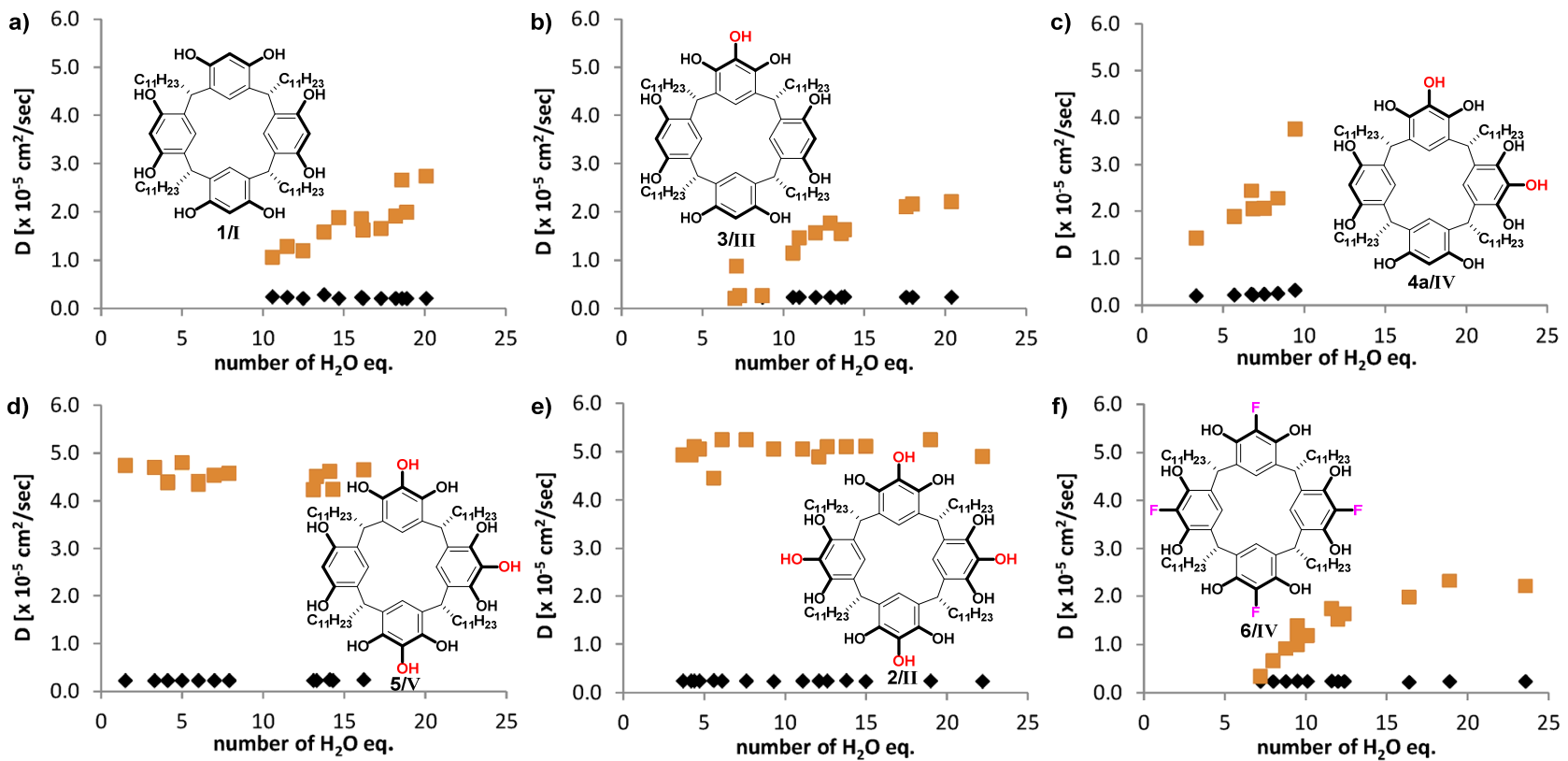

Figure 5: a - f) Influence of the water content on the diffusion coefficients D of the assemblies $(\bullet)$ and water $(\square)$. Experiments performed in $\mathrm{CDCl}_{3}$ solutions of the assemblies $(3.33-1.67 \mathrm{mmol} / \mathrm{L})$. 
However, if water is an integral part of the capsule, its diffusion value converges to the value of the assembly when the total amount of water decreases (assembly I, Figure 5a). Varying the water content of chloroform solutions of the novel catalytically active assemblies III, IV and VI (Figure 5 b, c, f) indicated that in these cases water is part of the hydrogen bond network, similar to structure I (Figure 5a). In contrast, the data obtained for the inactive assembly $\mathbf{V}$ (Figure 5d) implies that water does not take part in the formation of assembly $\mathbf{V}$; the same observation as was made for structure II. It should be noted that in the case of assembly $\mathbf{I V}$, due to an overlap between the water signal and signals of the assembly, only a few measurements resulted in reliable data points concerning the diffusion value of water. However, considering that the water signal is shifted significantly and that the diffusion values obtained are significantly lower than the values observed for the assemblies containing no water, we concluded that water is part of the hydrogen bond network of assembly IV.

In conclusion, the incorporation of water into the hydrogen bond network of the assembly correlates well with the catalytic activity observed. Interestingly, the assemblies containing water in the hydrogen bond network also displayed enhanced protonation in the presence of $\mathrm{HCl}$ (see previous chapter). These observations indicate a central role of the bound water molecules for the catalytic activity.

\section{Molecular Dynamics Simulations}

The results presented in the previous two chapters, indicate that water being part of the hydrogen bond network is essential in the protonation of the assembly by an external acid; thereby enabling catalysis within the host structures I, III, IV and VI. In order to learn more details about the protonation event inside the capsule, we turned to molecular dynamics (MD) simulations. Specifically, capsule I containing encapsulated geranyl acetate (7), and external $\mathrm{HCl}$ were submitted to QM/MM (DFT, PBE,${ }^{19}+\mathrm{D}$ leve ${ }^{20}$ ) MD simulations at $300 \mathrm{~K}$ using the $\mathrm{CP} 2 \mathrm{~K}$ code. ${ }^{21}$ The $\mathrm{QM}$ region consisted of six resorcinol units belonging to three adjacent resorcinarene molecules, one water molecule, one $\mathrm{HCl}$ molecule and geranyl acetate (7), whereas the rest of assembly I and the chloroform solvent molecules were treated at the MM level (see SI for computational details).

As the proton transfer from $\mathrm{HCl}$ to the carbonyl-oxygen of substrate 7 involves separate, relevant metastable states separated by high free energy barriers along the reaction path, standard MD is not suitable. Therefore, the sampling of the process was enhanced using Metadynamics ${ }^{22}$ (MetaD) implemented in the PLUMED2 code. ${ }^{23}$ To characterize the complex free energy landscape describing the proton migration from $\mathrm{HCl}$ throughout the complex hydrogen bond network, we used the method recently developed by Grifoni et al. $^{24}$

The simulation can be summarized as follows: (i) Energetically, the most favored pathway involves a direct protonation of the water at the capsule surface by $\mathrm{HCl}$ (Figure $6 \mathrm{a}$, state $\mathbf{A} \rightarrow \mathbf{B}$ ). The alternative pathway involving protonation of a phenol group, followed by rapid proton migration to a water molecule, is less likely (Figure S21). (ii) The formed chloride of the $\mathrm{H}^{3} \mathrm{O}^{+} / \mathrm{Cl}^{-}$ion pair is stabilized by coordination to the surrounding phenol groups of the resorcinarene molecules. It replaces the hydronium ion in the hydrogen bond network of capsule $\mathbf{I}$ and pushes the hydronium ion into the cavity (state B).

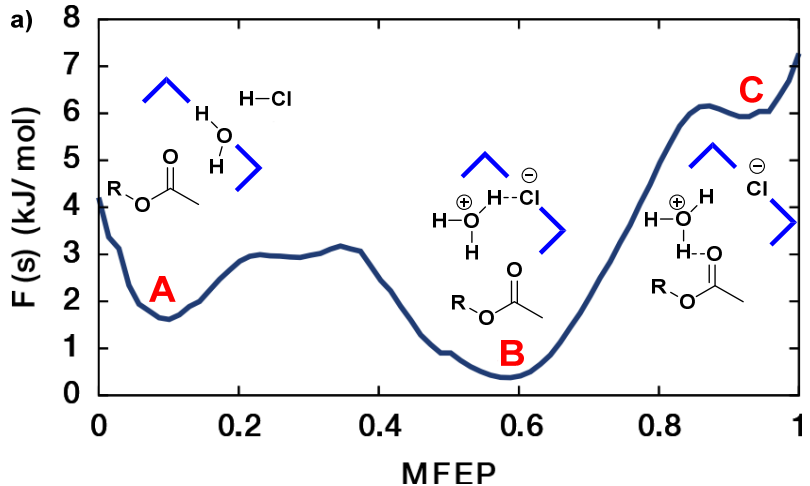

b)

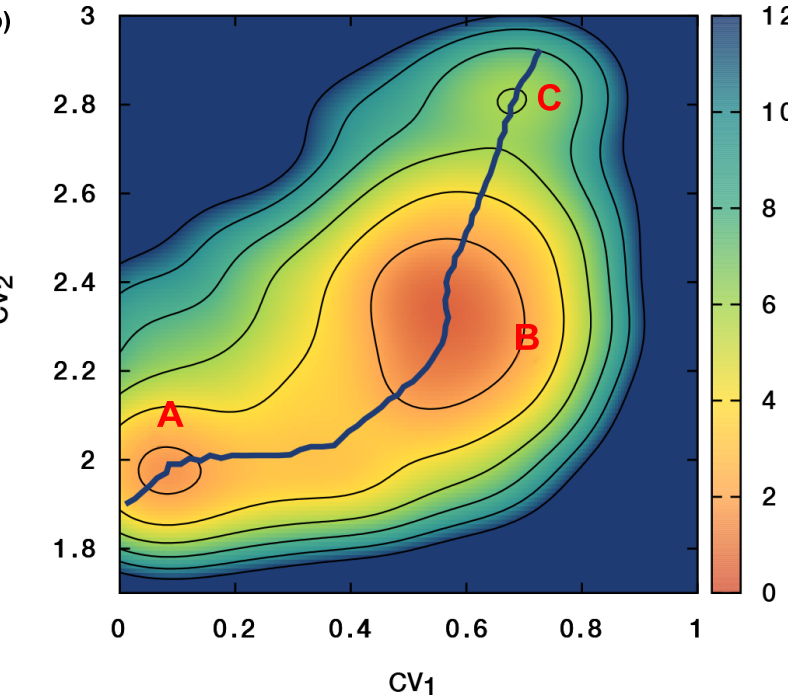

Figure 6: a) Free energy along the minimum free energy path (MFEP) showing the three states` (A, B and C) relative stabilities and free energy barriers separating them. b) Free energy surface for the geranyl acetate (7) protonation by means of $\mathrm{HCl}$ as co-catalyst for assembly $\mathbf{I}$ along the coordination of the carbonyl-oxygen with the water oxygen atom $\left(\mathrm{CV}_{1}\right)$ and the coordination of the water oxygen atoms with the acidic hydrogen atoms $\left(\mathrm{CV}_{2}\right)$. Letters $\mathrm{A}, \mathrm{B}$, and $\mathrm{C}$ label the minima corresponding to the metastable states referring to the initial neutral state, the intermediate formation of the $\mathrm{H}^{3} \mathrm{O}^{+} / \mathrm{Cl}^{-}$ion pair, and the final protonation of the carbonyl-oxygen by $\mathrm{H}_{3} \mathrm{O}^{+}$. The blue line passing through the three states represents the MFEP connecting them. The color bar represents the energy reported in $\mathrm{kJ} \cdot \mathrm{mol}^{-1}$.

(iii) Finally, the hydronium ion and the carbonyl of the geranyl acetate substrate form a very compact complex, sharing the proton (state C). Similar structures have been observed in other computational studies focusing on the acid catalyzed ester hydrolysis. ${ }^{25}$

To further analyze the results, we calculated the free energy surface following the reweighting procedure previously described. ${ }^{26}$ In order to extract useful and chemically meaningful information on the protonation process, two collective variables $\left(\mathrm{CV}_{1}\right.$ and $\left.\mathrm{CV}_{2}\right) \mathrm{de}-$ scribing the progressive protonation reaction of the carbonyl-oxygen have been selected. To be general in describing the fundamental chemical features, we used coordination numbers. These functions count how many atoms of a specific species are found within a cutoff sphere from the central atom. In the present case, $\mathrm{CV}_{1}$ accounts for the proximity of the carbonyl-oxygen and the water oxygen atoms. At the starting point of the simulation (Figure $6 \mathrm{~b}$, state A), $\mathrm{CV}_{1}$ is close to zero; after the formation of the final hydronium- 
carbonyl complex (state $\mathbf{C}$ ), it will be around one, as the water molecule gets close to the carbonyl-oxygen. The second variable $\left(\mathrm{CV}_{2}\right)$ accounts for the number of hydrogen atoms in close proximity to the water-oxygen. At the starting point of the simulation (state $\mathbf{A}$ ), $\mathrm{CV}_{2}$ is two, corresponding to the number of covalent bonds in the neutral water molecule. As the proton transfer proceeds, $\mathrm{CV}_{2}$ increases.

The minimum free energy path ${ }^{27}$ (MFEP) along the free energy surface is depicted in Figure 6a. This curve represents the minimum energy required during the process. It is worth noticing that state $\mathbf{B}$ in which the $\mathrm{H}^{+} \mathrm{O}^{+} / \mathrm{Cl}^{-}$ion pair is formed is the most stable state. The chloride anion is well stabilized by the surrounding phenol groups at the surface of the capsule. The estimated energy barrier for the dissociation process is only approx. $1.5 \mathrm{~kJ} \cdot \mathrm{mol}^{-1}$, much lower than the thermal barrier $\left(\mathrm{kB}_{\mathrm{B}} \sim 2.5 \mathrm{~kJ} \cdot \mathrm{mol}^{-1}\right)$. The picture is different when we consider the formation of the carbonyl/hydronium complex of state $\mathbf{C}$. Its formation is slowed down by a larger barrier of approx. $6 \mathrm{~kJ} \cdot \mathrm{mol}^{-1}$ and state $\mathbf{C}$ is less stable than state $\mathbf{B}$. Again, this result is in line with previous computational findings. ${ }^{25}$ The calculations, therefore, provide further evidence that water is indeed essential for the proton transfer process from the co-catalyst $\mathrm{HCl}$ onto the encapsulated substrate.

\section{Conclusion}

The experimental results obtained in this study, are summarized in Table 3. Taken together, these results strongly indicate that the decisive requirement for catalytic activity in the context of terpene cyclization is the incorporation of water molecules into the hydrogen bond network of the assembly. The crucial water molecule functions as a proton shuttle, delivering the proton onto the encapsulated substrate. If water is not incorporated into the assembly, this protonation mode is prevented, rendering these hosts catalytically inactive. This holds true even in the case where the host is able to encapsulate the substrate and stabilize ion pairs (assembly $\mathbf{V}$, Table 3 , entry 5 ). This finding has furthermore been validated by calculations, which confirm that the proposed intermediary states constitute the minimum free energy path.

Interestingly, the proposed protonation pathway may also provide insights into the puzzling observation that the chloride counter anion of the $\mathrm{HCl}$ co-catalyst does not interfere with the cationic cyclization cascade. Control experiments with $\mathrm{HCl}$, as well as other Bronsted or Lewis acids ${ }^{5 \mathrm{a}, 6,28}$ usually lead to counter anion quenching of cationic intermediates. Since the chloride anion is bound at the capsule surface (Figure 6a), it is prevented from quenching cationic intermediates inside the cavity of the capsule.
Table 3: Comparison of properties of macrocycles $\mathbf{1}-\mathbf{6}$ and the corresponding assemblies I - VI indicating a correlation between water being part of the hydrogen bond network and catalytic activity in the THT cyclization.

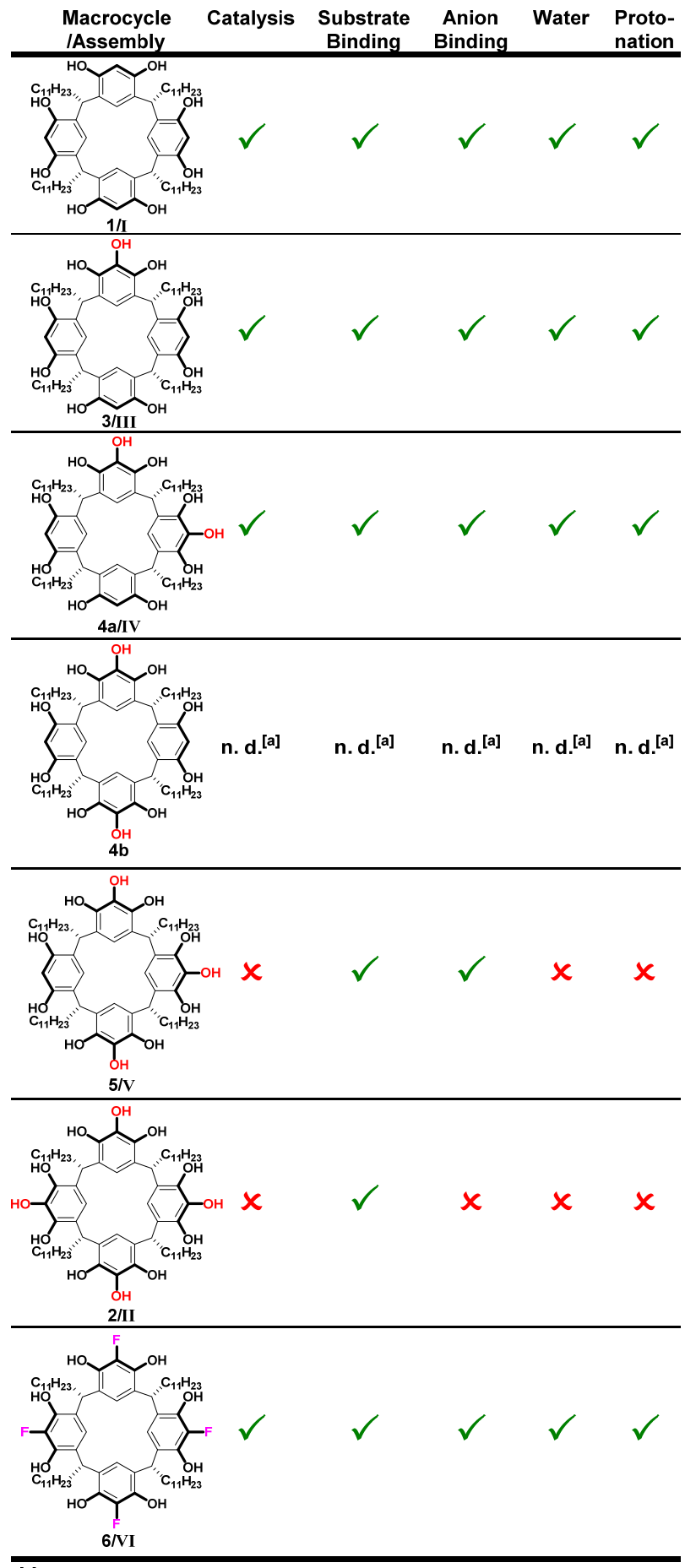

${ }^{[a]}$ Not determinded due to the insolubility of $\mathbf{4 b}$ in $\mathrm{CDCl}_{3}$. 


\section{Summary}

In summary, we presented the synthesis and characterization of four new macrocycles $\mathbf{3}-\mathbf{5}$ composed of different ratios of resorcinol and pyrogallol units as well as a new tetrafluorinated resorcinarene derivative 6 . With the exception of compound $4 \mathrm{~b}$, all derivatives self-assemble to dynamic, hexameric hydrogen-bonded assemblies in chloroform solution. The new assemblies III - VI together with assemblies I and II, were studied in detail and compared with respect to their catalytic activity in the monoterpene cyclization, their ability to encapsulate terpene substrates and ion pairs, their response to acid additive, and the amount of water incorporated into the hydrogen bond network. The experimental results strongly indicate a correlation between the catalytic activity and water being part of the assembly. QM/MM molecular dynamics simulations provided insights into the specific role of the water molecule in the protonation process of the encapsulated substrate. The incorporated water molecules likely act as a proton shuttle by transferring the proton from the acid co-catalyst $\mathrm{HCl}$ to the encapsulated substrate, which initiates the cyclization. Since the chloride counter anion is replacing one water molecule in the hydrogen bond network, it is immobilized and does not interfere with the cationic cyclization cascade reaction.

These findings finally reveal the activation mechanism inside capsule I, and decipher the prerequisites for catalytic activity. It, therefore, represents an important step towards the rational design of new supramolecular catalyst systems. We expect this finding to make a significant impact on future developments in the field of supramolecular catalysis, since the proposed model is likely transferable to other types of host systems.

\section{Associated content}

Supporting Information

The Supporting Information is available free of charge on the ACS Publications website at DOI:

Experimental details and NMR spectra of new compounds (PDF)

\section{Author information}

Corresponding Author

*konrad.tiefenbacher@unibas.ch; tkonrad@ethz.ch

Notes

The authors declare no competing financial interest.

\section{Acknowledgements}

This work was supported by funding from the European Research Council Horizon 2020 Programme (ERC Starting Grant 714620 TERPENECAT) and the Swiss National Science Foundation as part of the NCCR Molecular Systems Engineering. We thank PD Dr. Daniel Häussinger for assistance with the DOSY-NMR measurements. L.C. thanks JSPS and the Alexander von Humboldt Foundation for a postdoctoral fellowship. GM.P. thanks Prof. Michele Parrinello for fruitful discussions and Emanuele Grifoni for support and analysis of metadynamics simulations. All calculations were run on the ETHZ Euler-IV cluster.

\section{References}

1. (a) Kirby, A. J. Enzyme Mechanisms, Models, and Mimics. Angew. Chem. Int. Ed. 1996, 35 (7), 706-724; (b) Motherwell, W. B.; Bingham, M. J.; Six, Y. Recent progress in the design and synthesis of artificial enzymes. Tetrahedron 2001, 57 (22), 4663-4686; (c) GarciaViloca, M.; Gao, J.; Karplus, M.; Truhlar, D. G. How Enzymes Work: Analysis by Modern Rate Theory and Computer Simulations. Science 2004, 303 (5655), 186-195; (d) Zhang, X.; Houk, K. N. Why Enzymes Are Proficient Catalysts: Beyond the Pauling Paradigm. Acc. Chem. Res. 2005, 38 (5), 379-385; (e) Gao, J.; Ma, S.; Major, D. T.; Nam, K.; Pu, J.; Truhlar, D. G. Mechanisms and Free Energies of Enzymatic Reactions. Chem. Rev. 2006, 106 (8), 3188-3209; (f) Warshel, A.; Sharma, P. K.; Kato, M.; Xiang, Y.; Liu, H.; Olsson, M. H. M. Electrostatic Basis for Enzyme Catalysis. Chem. Rev. 2006, 106 (8), 3210-3235; (g) Ringe, D.; Petsko, G. A. How Enzymes Work. Science 2008, 320 (5882), 1428-1429; (h) Kamerlin, S. C. L.; Warshel, A. At the dawn of the 21 st century: Is dynamics the missing link for understanding enzyme catalysis? Proteins 2010, 78 (6), 1339-1375.

2. (a) Pluth, M. D.; Bergman, R. G.; Raymond, K. N. ProtonMediated Chemistry and Catalysis in a Self-Assembled Supramolecular Host. Acc. Chem. Res. 2009, 42 (10), 1650-1659; (b) Yoshizawa, M.; Klosterman, J. K.; Fujita, M. Functional Molecular Flasks: New Properties and Reactions within Discrete, Self-Assembled Hosts. Angew. Chem. Int. Ed. 2009, 48 (19), 3418-3438; (c) Meeuwissen, J.; Reek, J. N. Supramolecular catalysis beyond enzyme mimics. Nat. Chem. 2010, 2 (8), 615-21; (d) Wiester, M. J.; Ulmann, P. A.; Mirkin, C. A. Enzyme Mimics Based Upon Supramolecular Coordination Chemistry. Angew. Chem. Int. Ed. 2011, 50 (1), 114-137; (e) Marchetti, L.; Levine, M. Biomimetic Catalysis. ACS Catal. 2011, 1 (9), 1090-1118; (f) Ajami, D.; Rebek, J. More Chemistry in Small Spaces. Acc. Chem. Res. 2013, 46 (4), 990-999; (g) Raynal, M.; Ballester, P.; Vidal-Ferran, A.; van Leeuwen, P. W. N. M. Supramolecular catalysis. Part 2: artificial enzyme mimics. Chem. Soc. Rev. 2014, 43 (5), 1734-1787; (h) Leenders, S. H.; Gramage-Doria, R.; de Bruin, B.; Reek, J. N. Transition metal catalysis in confined spaces. Chem Soc Rev 2015, 44 (2), 433-48; (i) Brown, C. J.; Toste, F. D.; Bergman, R. G.; Raymond, K. N. Supramolecular catalysis in metal-ligand cluster hosts. Chem. Rev. 2015, 115 (9), 3012-35; (j) Zarra, S.; Wood, D. M.; Roberts, D. A.; Nitschke, J. R. Molecular containers in complex chemical systems. Chem. Soc. Rev. 2015, 44 (2), 419-432; (k) Catti, L.; Zhang, Q.; Tiefenbacher, K. Self-Assembled Supramolecular Structures as Catalysts for Reactions Involving Cationic Transition States. Synthesis 2016, 48 (03), 313-328; (1) Levin, M. D.; Kaphan, D. M.; Hong, C. M.; Bergman, R. G.; Raymond, K. N.; Toste, F. D. Scope and Mechanism of Cooperativity at the Intersection of Organometallic and Supramolecular Catalysis. J. Am. Chem. Soc. 2016, 138 (30), 9682-93; (m) Catti, L.; Zhang, Q.; Tiefenbacher, K. Advantages of Catalysis in Self-Assembled Molecular Capsules. Chem. Eur. J. 2016, 22 (27), 9060-9066; (n) Zhang, Q.; Catti, L.; Tiefenbacher, K. Catalysis inside the Hexameric Resorcinarene Capsule. Acc. Chem. Res. 2018, 51 (9), 2107-2114; (o) Mouarrawis, V.; Plessius, R.; van der Vlugt, J. I.; Reek, J. N. H. Confinement Effects in Catalysis Using Well-Defined Materials and Cages. Front. Chem. 2018, 6, 623; (p) Hong, C. M.; Bergman, R. G.; Raymond, K. N.; Toste, F. D. Self-Assembled Tetrahedral Hosts as Supramolecular Catalysts. Acc. Chem. Res. 2018, 51 (10), 2447-2455; (q) Zhu, Y.; Rebek Jr, J.; Yu, Y. Cyclizations catalyzed inside a hexameric resorcinarene capsule. Chem. Commun. 2019, 55 (25), 3573-3577; (r) Gaeta, C.; Talotta, C.; De Rosa, M.; La Manna, P.; Soriente, A.; Neri, P. The Hexameric Resorcinarene Capsule at Work: Supramolecular Catalysis in Confined Spaces. Chem. Eur. J. 2019, 25 (19), 4899-4913; (s) Zhang, Q.; Catti, L.; Syntrivanis, L. D.; Tiefenbacher, K. En route to terpene natural products utilizing supramolecular cyclase mimetics. Nat. Prod. Rep. 2019, $10.1039 / \mathrm{c} 9$ np00003h.

3. For recent examples see: (a) Wei, J.; Zhao, L.; He, C.; Zheng, S.; Reek, J. N. H.; Duan, C. Metal-Organic Capsules with NADH Mimics as Switchable Selectivity Regulators for Photocatalytic Transfer Hydrogenation. J. Am. Chem. Soc. 2019, 141 (32), 12707-12716; (b) Jans, A. C. H.; Caumes, X.; Reek, J. N. H. Gold Catalysis in (Supra)Molecular Cages to Control Reactivity and Selectivity. ChemCatChem 2019, 11 (1), 287-297; (c) Jongkind, L. J.; Elemans, J.; Reek, J. N. H. Cofactor Controlled Encapsulation of a Rhodium Hydroformylation Catalyst. Angew. Chem. Int. Ed. 2019, 58 (9), 2696-2699; (d) Bender, T. A.; Bergman, R. G.; Raymond, K. N.; Toste, F. D. A Supramolecular Strategy for Selective Catalytic Hydrogenation Independent of Remote Chain Length. J. Am. Chem. Soc. 2019, 141 (30), 11806-11810; (e) Bender, T. A.; Morimoto, M.; Bergman, R. G.; Raymond, K. N.; Toste, F. D. Supramolecular Host-Selective Activation of Iodoarenes by Encapsulated Organometallics. J. Am. Chem. Soc. 2019, 141 (4), 1701-1706; (f) Takezawa, H.; Kanda, T.; Nanjo, H.; Fujita, M. Site-Selective Functionalization of Linear Diterpenoids through U-Shaped Folding in a Confined Artificial Cavity. J. Am. Chem. Soc. 2019, 
141 (13), 5112-5115; (g) La Manna, P.; De Rosa, M.; Talotta, C.; Rescifina, A.; Floresta, G.; Soriente, A.; Gaeta, C.; Neri, P. Synergic Interplay Between Halogen Bonding and Hydrogen Bonding in the Activation of a Neutral Substrate in a Nanoconfined Space. Angew. Chem. Int. Ed. 2019, 10.1002/anie.201909865; (h) Gambaro, S.; De Rosa, M.; Soriente, A.; Talotta, C.; Floresta, G.; Rescifina, A.; Gaeta, C.; Neri, P. A hexameric resorcinarene capsule as a hydrogen bonding catalyst in the conjugate addition of pyrroles and indoles to nitroalkenes. Org. Chem. Front. 2019, 6 (14), 2339-2347; (i) Gambaro, S.; La Manna, P.; De Rosa, M.; Soriente, A.; Talotta, C.; Gaeta, C.; Neri, P. The Hexameric Resorcinarene Capsule as a Brønsted Acid Catalyst for the Synthesis of Bis(heteroaryl)methanes in a Nanoconfined Space. Front. Chem. 2019, 7 (687); (j) Angamuthu, V.; Petroselli, M.; Rahman, F.-U.; Yu, Y.; Rebek, J. Binding orientation and reactivity of alkyl $\alpha, \omega$-dibromides in water-soluble cavitands. Org. Biomol. Chem. 2019, 17 (21), 5279-5282; (k) Köster, J. M.; Häussinger, D.; Tiefenbacher, K. Activation of Primary and Secondary Benzylic and Tertiary Alkyl (sp3)C-F Bonds Inside a Self-Assembled Molecular Container. Front. Chem. 2019, 6 (639).

4. (a) MacGillivray, L. R.; Atwood, J. L. A chiral spherical molecular assembly held together by 60 hydrogen bonds. Nature 1997, 389 (6650), 469-472; (b) Avram, L.; Cohen, Y. Spontaneous Formation of Hexameric Resorcinarene Capsule in Chloroform Solution as Detected by Diffusion NMR. J. Am. Chem. Soc. 2002, 124 (51), 15148-15149; (c) Avram, L.; Cohen, Y.; Rebek Jr, J. Recent advances in hydrogen-bonded hexameric encapsulation complexes. Chem. Commun. 2011, 47 (19), 53685375 .

5. (a) Zhang, Q.; Tiefenbacher, K. Terpene cyclization catalysed inside a self-assembled cavity. Nat. Chem. 2015, 7 (3), 197-202; (b) Zhang, Q.; Catti, L.; Pleiss, J.; Tiefenbacher, K. Terpene Cyclizations inside a Supramolecular Catalyst: Leaving-Group-Controlled Product Selectivity and Mechanistic Studies. J. Am. Chem. Soc. 2017, 139 (33), 11482-11492; (c) Zhang, Q.; Rinkel, J.; Goldfuss, B.; Dickschat, J. S.; Tiefenbacher, K. Sesquiterpene Cyclisations Catalysed inside the Resorcinarene Capsule and Application in the Short Synthesis of Isolongifolene and Isolongifolenone. Nat. Catal. 2018, 1 (8), 609-615; (d) Zhang, Q.; Tiefenbacher, K. Sesquiterpene Cyclizations inside the Hexameric Resorcinarene Capsule: Total Synthesis of delta-Selinene and Mechanistic Studies. Angew. Chem. Int. Ed. 2019, 58 (36), 12688-12695.

6. Pronin, S. V.; Shenvi, R. A. Synthesis of highly strained terpenes by non-stop tail-to-head polycyclization. Nat. Chem. 2012, 4 (11), 915-920.

7. (a) Croteau, R. Biosynthesis and catabolism of monoterpenoids. Chem. Rev. 1987, 87 (5), 929-954; (b) Cane, D. E. Enzymic formation of sesquiterpenes. Chem. Rev. 1990, 90 (7), 1089-1103; (c) Christianson, D. W. Structural Biology and Chemistry of the Terpenoid Cyclases. Chem. Rev. 2006, 106 (8), 3412-3442; (d) Degenhardt, J.; Köllner, T. G.; Gershenzon, J. Monoterpene and sesquiterpene synthases and the origin of terpene skeletal diversity in plants. Phytochemistry 2009, 70 (15), 16211637; (e) Dickschat, J. S. Isoprenoids in three-dimensional space: the stereochemistry of terpene biosynthesis. Nat. Prod. Rep. 2011, 28 (12), 1917-1936; (f) Miller, D. J.; Allemann, R. K. Sesquiterpene synthases: passive catalysts or active players? Nat. Prod. Rep. 2012, 29 (1), 60-71; (g) Dickschat, J. S. Bacterial terpene cyclases. Nat. Prod. Rep. 2016, 33 (1), 87-110; (h) Christianson, D. W. Structural and Chemical Biology of Terpenoid Cyclases. Chem. Rev. 2017, 117 (17), 11570-11648.

8. Syntrivanis, L.-D.; Levi, S.; Prescimone, A.; Major, D. T.; Tiefenbacher, K. Four-Step Access to the Sesquiterpene Natural Product Presilphiperfolan-1 $\beta$-ol and Unnatural Derivatives via Supramolecular Catalysis. ChemRxiv 2019, 10.26434/chemrxiv.9891341.v1.

9. (a) Gerkensmeier, T.; Iwanek, W.; Agena, C.; Fröhlich, R.; Kotila, S.; Näther, C.; Mattay, J. Self-Assembly of 2,8,14,20-Tetraisobutyl5,11,17,23-tetrahydroxyresorc[4]arene. Eur. J. Org. Chem. 1999, 1999 (9), 2257-2262; (b) Atwood, J. L.; Barbour, L. J.; Jerga, A. Hydrogen-bonded molecular capsules are stable in polar media. Chem. Commun. 2001, (22), 2376-2377; (c) Shivanyuk, A.; Rebek, J. J. Hydrogen-bonded capsules in polar, protic solvents. Chem. Commun. 2001, (22), 2374-2375; (d) Atwood, J. L.; Barbour, L. J.; Jerga, A. Organization of the interior of molecular capsules by hydrogen bonding. Proc. Natl. Acad. Sci. U.S.A. 2002, 99 (8), 4837-4841; (e) Avram, L.; Cohen, Y. Discrimination of Guests Encapsulation in Large Hexameric Molecular Capsules in Solution: Pyrogallol[4]arene versus Resorcin[4]arene Capsules. J. Am. Chem. Soc. 2003, 125 (52), 16180-16181; (f) Avram, L.; Cohen, Y. Hexameric Capsules of Lipophilic Pyrogallolarene and Resorcinarene in Solutions as
Probed by Diffusion NMR: One Hydroxyl Makes the Difference. Org. Lett. 2003, 5 (18), 3329-3332; (g) Shivanyuk, A.; Friese, J. C.; Döring, S.; Rebek, J. Solvent-Stabilized Molecular Capsules. J. Org. Chem. 2003, 68 (17), 6489-6496; (h) Avram, L.; Cohen, Y. Self-Recognition, Structure, Stability, and Guest Affinity of Pyrogallol[4]arene and Resorcin[4]arene Capsules in Solution. J. Am. Chem. Soc. 2004, 126 (37), 11556-11563; (i) Guralnik, V.; Avram, L.; Cohen, Y. Unique Organization of Solvent Molecules Within the Hexameric Capsules of Pyrogallol[4]arene in Solution. Org. Lett. 2014, 16 (21), 5592-5595; (j) Avram, L.; Goldbourt, A.; Cohen, Y. Hexameric Capsules Studied by Magic Angle Spinning Solid-State NMR Spectroscopy: Identifying Solvent Molecules in Pyrogallol[4]arene Capsules. Angew. Chem. Int. Ed. 2016, 55 (3), 904-7.

10. Zhang, Q.; Catti, L.; Kaila, V. R. I.; Tiefenbacher, K. To catalyze or not to catalyze: elucidation of the subtle differences between the hexameric capsules of pyrogallolarene and resorcinarene. Chem Sci 2017, $8(2), 1653-1657$

11. (a) Elidrisi, I.; Negin, S.; Bhatt, P. V.; Govender, T.; Kruger, H. G.; Gokel, G. W.; Maguire, G. E. M. Pore formation in phospholipid bilayers by amphiphilic cavitands. Org. Biomol. Chem. 2011, 9 (12), 44984506; (b) Pietraszkiewicz, M.; Prus, P.; Pietraszkiewicz, O. Synthesis of novel, boron-containing cavitands derived from calix[4]resorcinarenes and their molecular recognition of biologically important polyols in Langmuir films. Tetrahedron 2004, 60 (47), 10747-10752; (c) Tan, S.-D.; Chen, W.H.; Satake, A.; Wang, B.; Xu, Z.-L.; Kobuke, Y. Tetracyanoresorcin[4]arene as a $\mathrm{pH}$ dependent artificial acetylcholine receptor. Org. Biomol. Chem. 2004, 2 (19), 2719-2721.

12. (a) Irwin, J. L.; Sherburn, M. S. Practical Synthesis of Selectively Functionalized Cavitands. J. Org. Chem. 2000, 65 (2), 602-605; (b) Irwin, J. L.; Sherburn, M. S. Optimized Synthesis of Cavitand Phenol Bowls. J. Org. Chem. 2000, 65 (18), 5846-5848.

13. Yamada, S.; Gavryushin, A.; Knochel, P. Convenient Electrophilic Fluorination of Functionalized Aryl and Heteroaryl Magnesium Reagents. Angew. Chem. Int. Ed. 2010, 49 (12), 2215-2218.

14. Punna, S.; Meunier, S.; Finn, M. G. A Hierarchy of Aryloxide Deprotection by Boron Tribromide. Org. Lett. 2004, 6 (16), 2777-2779.

15. Avram, L.; Cohen, Y. Diffusion NMR of molecular cages and capsules. Chem. Soc. Rev. 2015, 44 (2), 586-602.

16. Cori, O.; Chayet, L.; Perez, L. M.; Bunton, C. A.; Hachey, D. Rearrangement of linalool, geraniol, nerol and their derivatives. J. Org. Chem. 1986, 51 (8), 1310-1316.

17. Bryant, R. G. The NMR time scale. J. Chem. Educ. 1983, 60 (11), 933.

18. Avram, L.; Cohen, Y. The Role of Water Molecules in a Resorcinarene Capsule As Probed by NMR Diffusion Measurements. Org. Lett. 2002, 4 (24), 4365-4368.

19. Perdew, J. P.; Burke, K.; Ernzerhof, M. Generalized Gradient Approximation Made Simple. Phys. Rev. Lett. 1996, 77 (18), 3865-3868

20. Grimme, S.; Antony, J.; Ehrlich, S.; Krieg, H. A consistent and accurate ab initio parametrization of density functional dispersion correction (DFT-D) for the 94 elements H-Pu. J. Chem. Phys. 2010, 132 (15), 154104

21. Laino, T.; Mohamed, F.; Laio, A.; Parrinello, M. An Efficient Linear-Scaling Electrostatic Coupling for Treating Periodic Boundary Conditions in QM/MM Simulations. J. Chem. Theory. Comput. 2006, 2 (5), 1370-1378.

22. (a) Laio, A.; Parrinello, M. Escaping free-energy minima. Proc. Natl. Acad. Sci. U.S.A. 2002, 99 (20), 12562-12566; (b) Barducci, A.; Bussi, G.; Parrinello, M. Well-Tempered Metadynamics: A Smoothly Converging and Tunable Free-Energy Method. Phys. Rev. Lett. 2008, 100 (2), 020603.

23. Bonomi, M.; Bussi, G.; Camilloni, C.; Tribello, G. A.; Banáš, P.; Barducci, A.; Bernetti, M.; Bolhuis, P. G.; Bottaro, S.; Branduardi, D.; Capelli, R.; Carloni, P.; Ceriotti, M.; Cesari, A.; Chen, H.; Chen, W.; Colizzi, F.; De, S.; De La Pierre, M.; Donadio, D.; Drobot, V.; Ensing, B. Ferguson, A. L.; Filizola, M.; Fraser, J. S.; Fu, H.; Gasparotto, P.; Gervasio, F. L.; Giberti, F.; Gil-Ley, A.; Giorgino, T.; Heller, G. T.; Hocky, G. M.; Iannuzzi, M.; Invernizzi, M.; Jelfs, K. E.; Jussupow, A.; Kirilin, E.; Laio, A.; Limongelli, V.; Lindorff-Larsen, K.; Löhr, T.; Marinelli, F.; MartinSamos, L.; Masetti, M.; Meyer, R.; Michaelides, A.; Molteni, C.; Morishita T.; Nava, M.; Paissoni, C.; Papaleo, E.; Parrinello, M.; Pfaendtner, J.; Piaggi, P.; Piccini, G.; Pietropaolo, A.; Pietrucci, F.; Pipolo, S.; Provasi, D.; Quigley, D.; Raiteri, P.; Raniolo, S.; Rydzewski, J.; Salvalaglio, M.; Sosso, G. C.; Spiwok, V.; Šponer, J.; Swenson, D. W. H.; Tiwary, P.; Valsson, O.; Vendruscolo, M.; Voth, G. A.; White, A.; The, P. c. Promoting transparency 
and reproducibility in enhanced molecular simulations. Nat. Methods 2019, $16(8), 670-673$.

24. Grifoni, E.; Piccini, G.; Parrinello, M. Microscopic description of acid-base equilibrium. Proc. Natl. Acad. Sci. U.S.A. 2019, 116 (10), 4054-4057.

25. (a) Gómez-Bombarelli, R.; Calle, E.; Casado, J. Mechanisms of Lactone Hydrolysis in Acidic Conditions. J. Org. Chem. 2013, 78 (14), 6880-6889; (b) Shi, H.; Wang, Y.; Hua, R. Acid-catalyzed carboxylic acid esterification and ester hydrolysis mechanism: acylium ion as a sharing active intermediate via a spontaneous trimolecular reaction based on density functional theory calculation and supported by electrospray ionization-mass spectrometry. Phys. Chem. Chem. Phys. 2015, 17 (45), 30279-30291.

26. Valsson, O.; Tiwary, P.; Parrinello, M. Enhancing Important Fluctuations: Rare Events and Metadynamics from a Conceptual Viewpoint. Annu. Rev. Phys. Chem. 2016, 67 (1), 159-184.

27. (a) Jonsson, H.; Mills, G.; Jacobsen, K. W. Nudged elastic band method for finding minimum energy paths of transitions. In Classical and Quantum Dynamics in Condensed Phase Simulations, 385-404; (b) Maragliano, L.; Fischer, A.; Vanden-Eijnden, E.; Ciccotti, G. String method in collective variables: Minimum free energy paths and isocommittor surfaces. J. Chem. Phys. 2006, 125 (2), 024106.

28. (a) Andersen, N. H.; Syrdal, D. D. Chemical simulation of the biogenesis of cedrene. Tetrahedron Lett. 1972, 13 (24), 2455-2458; (b) Yoshimoto, O.; Yoshio, H. Electrophile Induced Cyclization of Farnesol. Chem. Lett. 1972, 1 (3), 263-266; (c) McCormick, J. P.; Barton, D. L. Studies in $85 \%$ H3PO4-II: On the role of the $\alpha$-terpinyl cation in cyclic monoterpene genesis. Tetrahedron 1978, 34 (3), 325-330. 